\title{
The occurrence of chloroplast peripheral reticulum in grasses: a matter of phylogeny or a matter of function?
}

\author{
Jarosław Szczepanik · Paweł Sowiński
}

Received: 5 December 2013/Accepted: 7 January 2014/Published online: 23 January 2014

(C) The Author(s) 2014. This article is published with open access at Springerlink.com

\begin{abstract}
The chloroplast peripheral reticulum (PR) is a structure of unknown function. Some authors postulated that it is a characteristic feature of $\mathrm{C}_{4}$ plants, although it was reported from $\mathrm{C}_{3}$ species as well. It is unknown whether the occurrence of PR follows a phylogenetic (it is found in clades containing $\mathrm{C}_{4}$ species, regardless of the photosynthetic type) or functional (photosynthetic pathway dependent) pattern. Here, we present a phylogenetically controlled analysis of the occurrence, form and functional aspects of PR in grasses. The occurrence of the PR follows a functional and not a phylogenetic pattern. Its most elaborated form (PR type I) is a unique feature of $\mathrm{C}_{4}$ species. Although PR was found in some of the studied $C_{3}$ grasses, it was always less developed than $\mathrm{PR}$ in the chloroplasts of Kranz mesophyll cells of $\mathrm{C}_{4}$ species. The size of $\mathrm{PR}$ in $\mathrm{C}_{4}$ plants was found to increase when the plants were grown under low light intensity. Additional observations, such as a negative correlation between PR size and chloroplast surface and PR occurrence in vicinity of mitochondria or plasmodesmata, suggest that PR may play some role in $\mathrm{C}_{4}$ metabolism.
\end{abstract}

Communicated by Z. Gombos.

J. Szczepanik $(\bowtie) \cdot$ P. Sowiński

Department of Plant Molecular Ecophysiology, Faculty of

Biology, University of Warsaw, ul. Miecznikowa 1,

02-096 Warsaw, Poland

e-mail: jarossz@biol.uw.edu.pl

P. Sowiński

Plant Biochemistry and Physiology Department, Plant Breeding and Acclimatization Institute, National Research Institute, Radzików, 05-870 Błonie, Poland
Keywords $\mathrm{C}_{4}$ photosynthesis - Peripheral reticulum . Chloroplast $\cdot$ Mitochondria $\cdot$ Plasmodesmata

\section{Introduction}

The chloroplast peripheral reticulum (PR) is a system of tubes and vesicles continuous with the chloroplast inner membrane (Laetsch 1974; Wise 2006). This structure was first described by Shumway and Weier (1967) for maize chloroplast, and soon it was reported in many other species. It was argued whether PR is an artifact generated during transmission electron microscopy (TEM) protocols (Laetsch 1974). Bruhl and Perry (1995) ruled out this possibility using different buffers and several fixative types, concentrations and fixation time variants for the leaves of several sedge species. PR was present in the chloroplasts regardless of the TEM protocol used. Wise and Harris (1984) recognized three distinct morphologies of PR: single or double rows of tubules around the entire (or most) periphery of the chloroplast (here, it will be referred to as PR type I), large groupings of tubules and vesicles in certain regions of the plastid's periphery (PR type II), and individual vesicles or saccules attached to the chloroplast inner membrane (PR type III).

Several lines of evidence suggest that PR could represent an adaptation for increased transport into/out of the chloroplast by increasing surface area of the chloroplast inner envelope, which controls metabolite exchange between the plastid and the cytoplasm (Heldt and Saur 1971). This can especially be true for type I and II PR. PR type III may represent either poorly developed PR or transport vesicles from the inner envelope to the thylakoids (Westphal et al. 2003). While type II and III PR was reported from numerous plant species, regardless of their 
carbon assimilation mode, the occurrence of PR type I seems to be confined to $\mathrm{C}_{4}$ species only (Wise and Harris 1984). Generally, PR seems to be ubiquitous in photosynthetic cells of $\mathrm{C}_{4}$ plants, both monocots and dicots (Black and Mollenhauer 1971; Chapman et al. 1975; Gracen et al. 1972; Hilliard and West 1971; Liu and Dengler 1994; Osmond 1971; Rosado-Alberio et al. 1968; Slack et al. 1969). It was noticed, that in $\mathrm{C}_{4}$ plants, PR may differ in both types of photosynthetically active cells. PR occurs more often, and is more pronounced (type I only), in the Kranz mesophyll (KMS) cells, where the primary carbon assimilation takes place (Edwards and Voznesenskaya 2011), while PR in the bundle sheath (BS) cells, where the primary carbon reduction is conducted, it may belong to either of the three types (Wise and Harris 1984). In that context, one could hypothesize that occurrence of the PR is related to $\mathrm{C}_{4}$ photosynthesis so it follows a functional pattern.

One cannot exclude that the abundance of PR in plastids of $\mathrm{C}_{4}$ species can reflect some phylogenetic (i.e., $\mathrm{PR}$ is a characteristic feature of clades within plant families containing $\mathrm{C}_{4}$ species) rather than physiological pattern, however, papers focusing on the occurrence of PR in different systematical groups are scarce. Gracen et al. (1972) have studied PR content in the chloroplasts of several $\mathrm{C}_{4}$ and $\mathrm{C}_{3}$ grasses. Unfortunately, no $\mathrm{C}_{4}$ species (only a $\mathrm{C}_{3}-\mathrm{C}_{4}$ intermediate) from the PACMAD clade-a group of tropical and subtropical grasses (subfamilies Panicoideae, Aristidoideae, Chloridoideae, Micrairoideae, Arundinoideae, and Danthonioideae) containing all $\mathrm{C}_{4}$ taxa within Poaceae (GPWG II 2012)—was included into this study. Bruhl and Perry (1995) investigated several sedges, representing three different $\mathrm{C}_{4}$ lineages, including two $\mathrm{C}_{3}$ species. These authors found that PR was absent from the chloroplasts of any $\mathrm{C}_{3}$ sedge they studied. However, $\mathrm{C}_{3}$ and $\mathrm{C}_{3}-\mathrm{C}_{4}$ intermediate species studied by Bruhl and Perry belonged to one genus only. Although taxonomic data on the appearance of $\mathrm{PR}$ in $\mathrm{C}_{4}$ and $\mathrm{C}_{3}$ plants are scarce, the hypothesis on phylogenetic pattern of $\mathrm{PR}$ abundance cannot be excluded.

The aim of the presented study is to check whether the occurrence of the chloroplast PR in grasses follows the phylogenetic or physiological pattern. To verify the "phylogenetic" hypothesis we compared chloroplast ultrastructure in regards to $\mathrm{PR}$ occurrence in eight grass species, including three $\mathrm{C}_{3}$ species from the PACMAD clade, which contains all $\mathrm{C}_{4}$ Poaceae. $\mathrm{C}_{4}$ species studied here belong to three different $\mathrm{C}_{4}$ lineages. To test the "functional" hypothesis, we assumed that PR should accumulate stronger in plants under conditions promoting photosynthetic activity. To this end, plants were grown under two different light conditions-medium and high intensities.

\section{Materials and methods}

Plant material and culture

Four $\mathrm{C}_{4}$ and four $\mathrm{C}_{3}$ species were chosen for studies (Table 1). Phylogenetic relationships between studied species are shown in Fig. 1. Three of the $\mathrm{C}_{3}$ species are from the PACMAD clade, containing all $\mathrm{C}_{4}$ grasses. Selected $\mathrm{C}_{4}$ species represent different biochemical subtypes of $\mathrm{C}_{4}$ photosynthesis and different types of Kranz anatomy: E. crus-galli-NADP-ME, classical NADP-ME anatomy, E. albensis, P. miliaceum-NAD-ME, classical NAD-ME anatomy, $M$. maximus-PEP-CK, classical PEP-CK anatomy. Three of the $\mathrm{C}_{3}$ species belong to the PACMAD clade, and $T$. aestivum is a representative of the Bambusoideae, Ehrhartoideae, Pooideae (BEP) clade, comprised of $\mathrm{C}_{3}$ species only. After germination seeds were transferred to Hoagland nutrient solution changed three times a week. Plants were grown in a growth chamber under a $14 / 10 \mathrm{~h}$ day/night photoperiod and $24 / 22{ }^{\circ} \mathrm{C}$ day/night temperature (Jończyk et al. 2011). During each experiment, the plants were grown under two different light intensities: 100 and $500 \mu \mathrm{mol}$ quanta $\mathrm{m}^{-2} \mathrm{~s}^{-1}$. Fully developed third to fifth leaves were harvested for further studies.

\section{TEM protocol}

Middle leaf lamellae from three different individuals per species, per each of two independent experiments were harvested for TEM. Two $2 \mathrm{~mm} \times 1 \mathrm{~mm}$ pieces were cut from each leaf and placed in the fixative [50 mM HEPES; $\mathrm{pH} \mathrm{7.0,2 \% (w/v)} \mathrm{paraformaldehyde} \mathrm{and} 2 \%$ (v/v) glutaraldehyde] for $4 \mathrm{~h}$ with a fixative change after first $2 \mathrm{~h}$. Postfixation in $2 \%$ osmium tetroxide (aqueous solution) with $0.8 \%$ potassium ferricyanide - a technique reported to preferentially stain PR and membranes of the chloroplast envelope (Lawton 1988; Mosejev et al. 1987)—was conducted overnight. Next, the material was dehydrated in ethanol graded series, embedded in Spurr's resin, cut into ultrathin sections of $80 \mathrm{~nm}$ and immobilized on copper slot grids with a Leica ultramicrotome, and contrasted in uranyl acetate ( $2 \%$ aqueous solution). The samples were analyzed with an electron microscope (JEM-1400, JEOL, Japan) at the Laboratory of Electron Microscopy, Nencki Institute of Experimental Biology, Warsaw at $80 \mathrm{kV}$, and photographed with a high resolution digital camera (CCD MORADA, SiS-Olympus, Germany).

Biometric analysis

For each experimental variant (species and light intensity) at least 20 chloroplasts in KMS and BS cells were analyzed. In each individual KMS chloroplast the border 
Table 1 List of grass species used in the study

\begin{tabular}{lllll}
\hline Species & Subfamily & Tribe/clade & $\mathrm{C}_{3} / \mathrm{C}_{4}$ & Seed source \\
\hline Echinochloa crus-galli & Panicoideae & Paniceae/Boivinellinae & $\mathrm{C}_{4}$ & Warsaw, Ochota \\
Eragrostis albensis & Chloridoideae & Eragrostideae & $\mathrm{C}_{4}$ & Warsaw, Ochota \\
Homopholis proluta & Panicoideae & Paniceae/Homopholis clade & $\mathrm{C}_{3}$ & B \& T World Seeds \\
Megathyrsus maximus & Panicoideae & Paniceae/Melinidinae & $\mathrm{C}_{4}$ & QAS, Toowoomba, Australia \\
Panicum bisulcatum & Panicoideae & Paniceae/Sacciolepis clade & $\mathrm{C}_{3}$ & AusPGRIS, AusTRCF 68818 \\
Panicum miliaceum & Panicoideae & Paniceae/Panicinae & $\mathrm{C}_{4}$ & Warsaw, Ochota \\
Phragmites australis & Arundinoideae & Arundineae & $\mathrm{C}_{3}$ & Warsaw, Służew \\
Triticum aestivum cult. San Pastorio & Pooideae & Triticeae & $\mathrm{C}_{3}$ & IHAR, Radzików \\
\hline
\end{tabular}

Systematic classification after GPWG II (2012)

AusPGRIS Australian Plant Genetic Resources Information System, IHAR Plant Breeding and Acclimatization Institute, QAS Queensland Agricultural Seeds

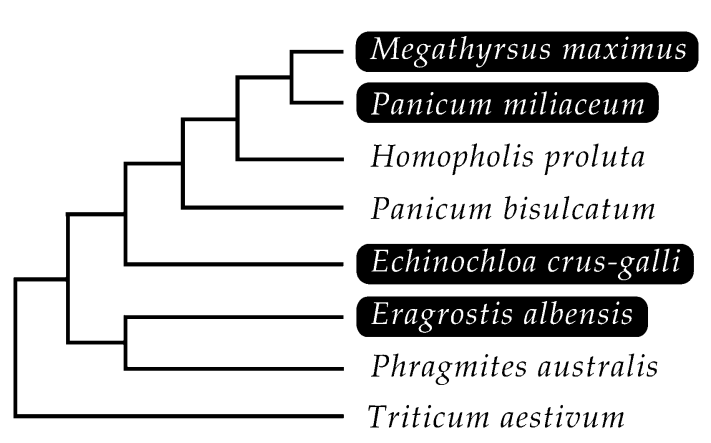

Fig. 1 A cladogram showing phylogenetic relationships between studied species $\left(\mathrm{C}_{4}\right.$ taxa are shown in black boxes). All taxa, excluding Triticum aestivum belong to the PACMAD clade (subfamilies Panicoideae, Aristidoideae, Chloridoideae, Micrairoideae, Arundinoideae, and Danthonioideae). Three different $\mathrm{C}_{4}$ lineages can be seen. Phylogeny after GPWG II (2012)

between PR zone and the stroma was determined in the longitudinal cross-sections of the chloroplasts. The percentage of the area occupied by PR (PRA) was determined by subtracting the area of the chloroplast cross-section inside the PR zone (ICA) from the total chloroplast crosssection area (TCA), using the following equation:

$\mathrm{PRA}=\frac{\mathrm{TCA}-\mathrm{ICA}}{\mathrm{TCA}} 100 \%$

To assess whether PR in the chloroplasts increases the size of membrane area or whether its size is just a function of chloroplast shape (i.e., it is higher only in oblong or highly lobed/indented plastids), shape analysis of the chloroplasts was conducted. Shape complexity was determined by calculating parameters proposed by Montero and Bribiesca (2009)—perimeter-area ratio (PARA):

PARA $=\frac{P}{\text { TCA }}$,

where $P$ is chloroplast perimeter, roundness $(R)$ :
$R=\frac{4 \mathrm{TCA}}{\pi \mathrm{MA}^{2}}$,

where MA is the major axis of the chloroplast, and compactness $(C)$ :

$C=\frac{P^{2}}{4 \pi \mathrm{TCA}}$.

All biometric parameters were calculated using ImageJ software. Each KMS chloroplast was analyzed twice. In BS cells of some species, where the PR content was low and the overall chloroplast size was large, any attempts to measure PRA were prone to error. In such cases, PRA was estimated only qualitatively.

\section{Results}

Peripheral reticulum in the leaves of $\mathrm{C}_{3}$ and $\mathrm{C}_{4}$ species

Peripheral reticulum was present in both KMS and BS chloroplasts of all $\mathrm{C}_{4}$ species studied. While in KMS chloroplasts it was always PR type I, and in BS cells chloroplasts type II and III prevailed (with the exception of E. crus-galli, where BS chloroplast contained PR type I) (Fig. 2). In all $C_{3}$ grasses studied, PR was absent, from at least some chloroplasts, both in mesophyll (M) and BS cells. If present, it was usually PR type III (type II was only noticed in some chloroplasts of $H$. proluta and T. aestivum). In many plastids only a few vesicles on entire chloroplast cross-section could be seen (Fig. 3). PR showed similar degree of development in $\mathrm{M}$ and $\mathrm{BS}$ chloroplasts. In $P$. australis PR was present in neither M nor BS plastids. However, invaginations of the entire chloroplasts were frequently observed in $\mathrm{M}$ cells (Fig. 3). Another $\mathrm{C}_{3}$ species which almost lacked PR was P. bisulcatum. Here, only single vesicles could be observed in 
BS

LL
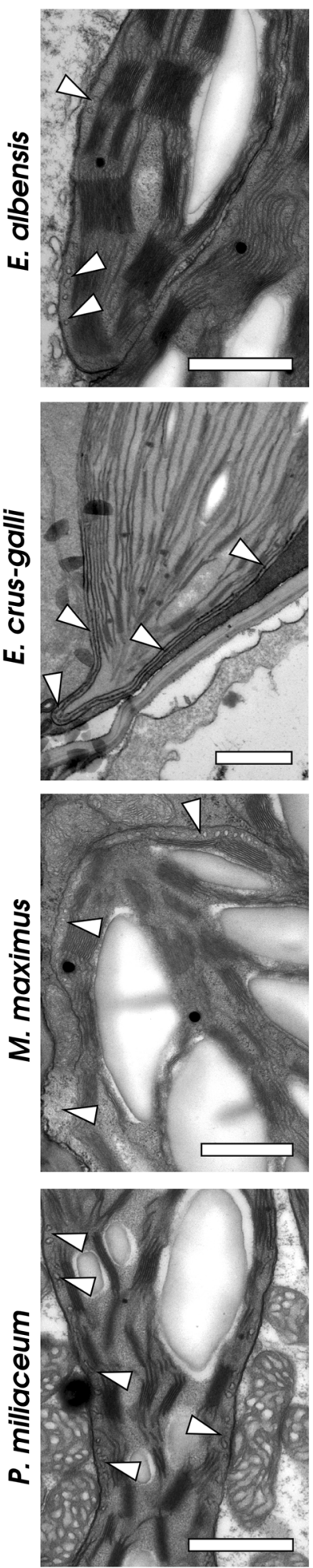

HL
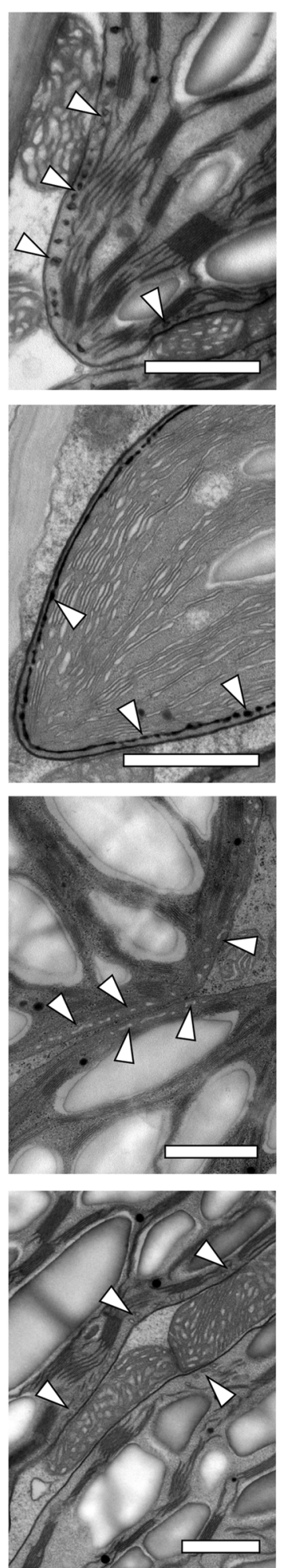

KMS

LL
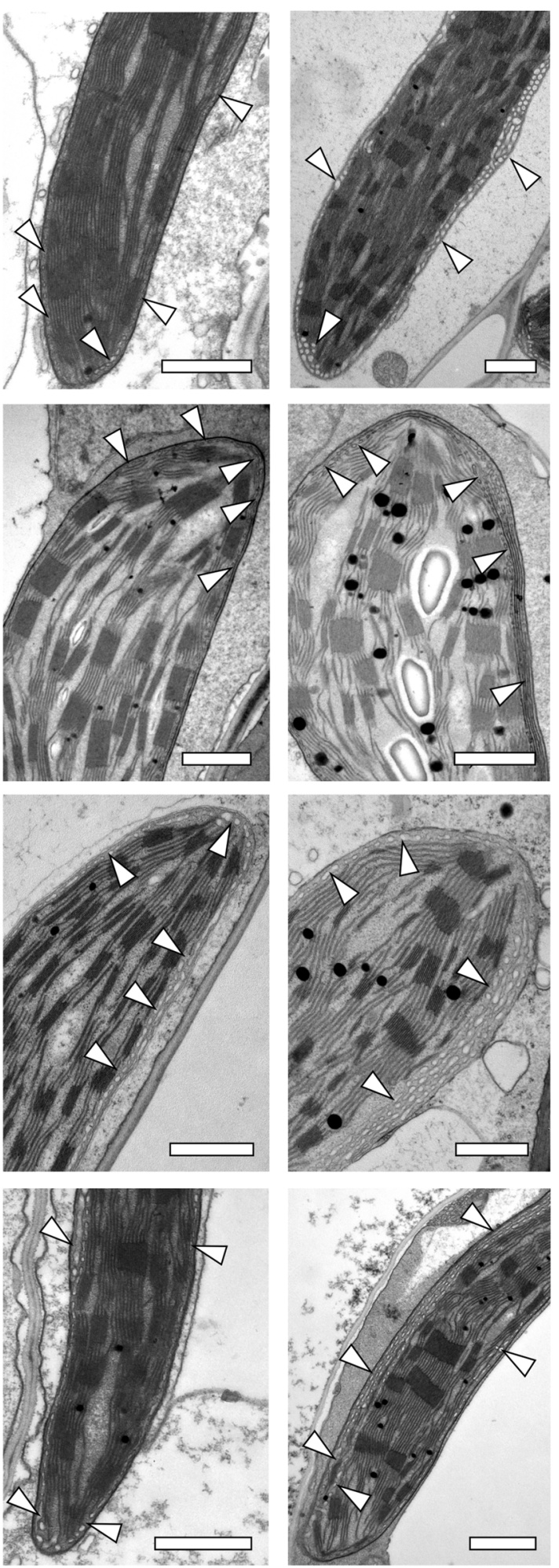
4Fig. 2 Peripheral reticulum (arrow heads) in Kranz mesophyll (KMS) and bundle sheath (BS) chloroplasts of four different $\mathrm{C}_{4}$ grasses grown at light intensities of 100 (LL) and $500 \mu \mathrm{mol}$ quanta $\mathrm{m}^{-2} \mathrm{~s}^{-1}(\mathrm{HL})$, scale bars $1 \mu \mathrm{m}$. Note that PR is more developed in HL plants, especially in KMS chloroplast. Also notice that BS chloroplast of E. crus-galli has more extensive network of vesicles than other species

the plastids of both cell types. In H. proluta and T. aestivum vesicles could be seen.

The effect of light intensity during growth on PR content in chloroplasts of $\mathrm{C}_{3}$ and $\mathrm{C}_{4}$ grasses

In $\mathrm{C}_{4}$ species, $\mathrm{PR}$ tends to be more developed in plants grown under higher irradiance, both in KMS and BS chloroplasts (Fig. 2). The difference between both light intensities was most evident in KMS plastids (Fig. 2). Here, chloroplasts of plants grown under $500 \mu \mathrm{mol}$ quanta $\mathrm{m}^{-2} \mathrm{~s}^{-1}$ had about twice as much PR as the plastids from plants grown at light intensity of $100 \mu \mathrm{mol}$ quanta $\mathrm{m}^{-2} \mathrm{~s}^{-1}$ (Table 2). The observed differences were statistically significant for all $\mathrm{C}_{4}$ species studied. BS chloroplasts from $\mathrm{C}_{4}$ plants grown at different light intensities were similar in appearance (Fig. 2). PR occupied $<5 \%$ of the total BS chloroplast cross-section area. Due to such small PRA values in BS chloroplasts, several measurements on the same chloroplast differed considerably. In $\mathrm{C}_{3}$ species, positive correlation between PR content and light intensity was visible only in $H$. proluta and T. aestivum (Fig. 3).

\section{Chloroplast shape and PR size}

Pearson product-moment correlation coefficients for the dependence of the percentage of chloroplast cross-section occupied by the peripheral reticulum (PRA) from perimeter to area ratio (PARA), roundness $(R)$ and compactness (C) of the KMS chloroplasts in $\mathrm{C}_{4}$ species are shown in Table 2. Small or medium correlation was found between chloroplast roundness or chloroplast compactness and the PRA in KMS chloroplasts. However, both the direction and strength of this correlation were not uniform across the species or if both light intensity variants from individual species were compared. The correlation between PRA and the perimeter to area ratio was medium to strong in all studied groups. In addition, it was always a negative correlation and it was stronger in plants grown at higher light intensity.

PR contact with plasmodesmata and mitochondria

In all $\mathrm{C}_{4}$ species studied, PR of both KMS and BS chloroplasts was sometimes in close proximity of endoplasmic reticulum (ER) of plasmodesmata (PD) (Fig. 4a-d). Such proximity was observed for all PD type between photosynthetically active cells (KMS/BS, KMS/KMS, BS/BS). However, only a small portion of each type of PD was adjacent to the PR of the chloroplasts. In E. crus-galli and M. maximus both KMS and BS chloroplasts were observed near KMS/BS plasmodesmata. In E. albensis and P. milliaceum PR occured more often on BS side of the PD. Black filling of ER and desmotubule (Fig. 4a, c) is a normal phenomenon when osmium ferricyanide stain is used (Mosejev et al. 1987). In all four species PR in BS chloroplasts was usually enlarged near mitochondria (Fig. $4 \mathrm{e}-$ h). This was especially evident in E. albensis, P. milliaceum and M. maximus. Apparently, some mitochondria developed structures similar to PR.

\section{Discussion}

The reported study aims to find out whether the occurrence of the chloroplast PR in grasses follows phylogenetic or functional pattern. The results show that PR cannot be seen as a synapomorphy for the PACMAD clade. It is also found outside PACMAD grasses, and some species belonging to this clade do not possess PR in their chloroplasts (Figs. 1, $2,3)$. Therefore, there is no phylogenetic pattern in the occurrence of $\mathrm{PR}$ in grasses. In contrast, a physiological pattern $\left(\mathrm{C}_{3}\right.$ or $\left.\mathrm{C}_{4}\right)$ can be found, with $\mathrm{PR}$ occurring predominantly in $\mathrm{C}_{4}$ species, especially when PR size is not taken into account. As noted by Wise and Harris (1984), PR type I occurs only in $\mathrm{C}_{4}$ plants. Here, we report for the first time, that this pattern is also found in closely related $\mathrm{C}_{3}$ and $\mathrm{C}_{4}$ species. Although $\mathrm{PR}$ can be present in $\mathrm{C}_{3}$ species, it is PR type II at most (Fig. 3). It seems that PR type $\mathrm{I}$ is particular trait of $\mathrm{C}_{4}$ species.

Although $\mathrm{PR}$ is found in all studied $\mathrm{C}_{4}$ species, it also appears in two $\mathrm{C}_{3}$ species out of four studied, what does not contradict earlier observations of PR in the chloroplasts of some $\mathrm{C}_{3}$ and CAM plants (Laetsch 1974; Wise and Harris 1984). There is a high probability that $P R$ is present in the chloroplasts of most $\mathrm{C}_{4}$ species, however, it is not a general rule, and some exceptions are found (Ueno et al. 1988). Any controversies about PR being a feature of $\mathrm{C}_{4}$ plants may result from not distinguishing Wise and Harris' PR type I from PR in general. PR type I is found mostly in KMS cells, what corresponds with other reports (Gracen et al. 1972; Laetsch 1974; Wise 2006). PR type I is also present in BS chloroplasts of a E. crus-galli (Fig. 2). The significance of this observation will be discussed in detail later. PR type II and III can occur in both $\mathrm{C}_{3}$ and $\mathrm{C}_{4}$ plants. In the case of $\mathrm{C}_{4}$ species, these types are common in $\mathrm{BS}$ chloroplasts.

Chloroplast ultrastructure is an important component of the photosynthetic apparatus light acclimation, regardless 
BS

\section{LL}
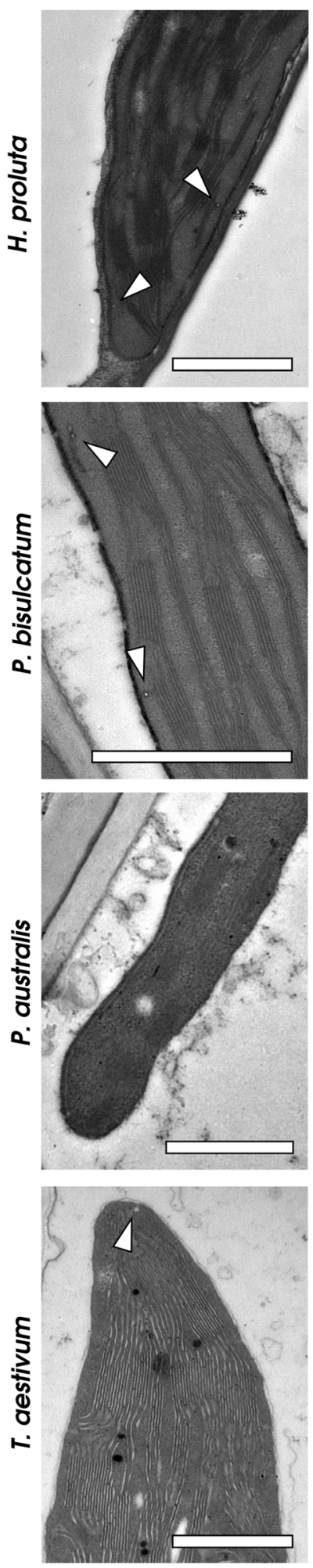
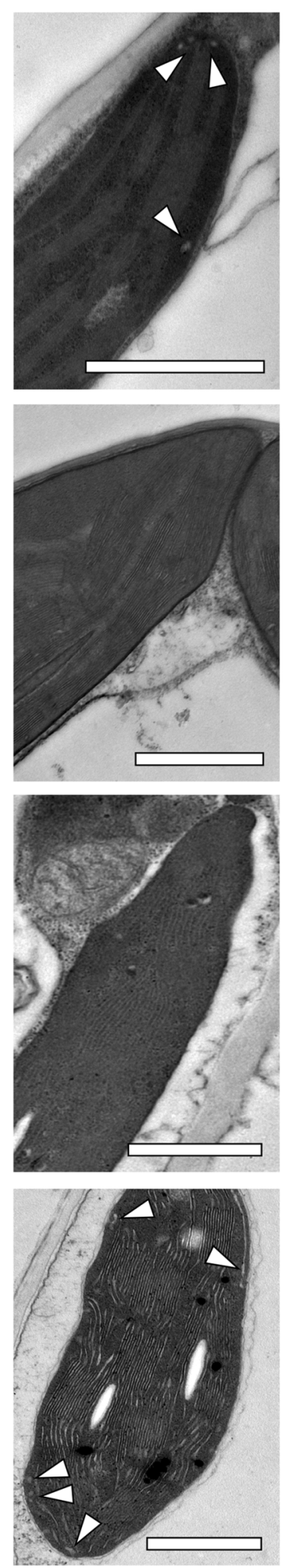

M

LL
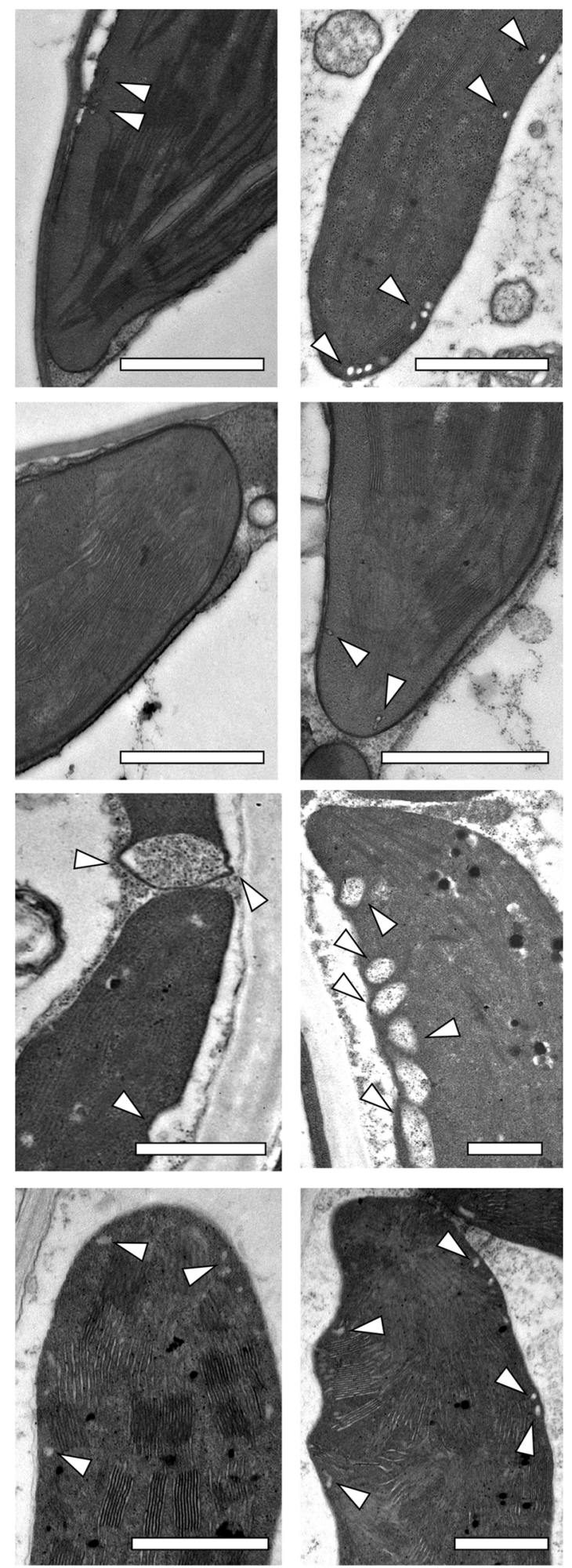
4Fig. 3 Peripheral reticulum (arrow heads) in mesophyll (M) and bundle sheath (BS) chloroplasts of four different $\mathrm{C}_{3}$ grasses grown at light intensities of 100 (LL) and $500 \mu \mathrm{mol}$ quanta $\mathrm{m}^{-2} \mathrm{~s}^{-1}$ (HL), scale bars $1 \mu \mathrm{m}$. Note the lack of PR in P. bisulcatum (only single vesicles are visible) and $P$. australis (here, plastid invaginations can be seen). PR seems to increase in HL grown plants only for $H$. proluta and T. aestivum

of plant's photosynthetic pathway (Drożak and Romanowska 2006; Pearcy and Franceschi 1986; Walters 2005; Wise 2006). Light-dependent changes of PR size in KMS plastids of $\mathrm{C}_{4}$ plants may be a part of this process. An

Table 2 Chloroplast peripheral reticulum (PR) size in bundle sheath (BS) and mesophyll/Kranz mesophyll (M/KMS) chloroplasts (expressed as a percentage of chloroplast longitudinal cross-section

\begin{tabular}{|c|c|c|c|c|c|}
\hline \multirow[t]{2}{*}{ Species } & \multicolumn{2}{|l|}{ BS } & \multicolumn{2}{|l|}{ KMS } & \multirow[t]{2}{*}{ PR type } \\
\hline & 100 & 500 & 100 & 500 & \\
\hline \multicolumn{6}{|l|}{$\mathrm{C}_{4}$ species } \\
\hline E. albensis & ++ & ++ & $8.64 \pm 1.69^{\mathrm{a}}$ & $17.29 \pm 2.25^{\mathrm{a}}$ & II, III (BS), I (KMS) \\
\hline E. crus-galli & $3.54 \pm 1.39$ & $3.58 \pm 0.33$ & $8.68 \pm 1.61^{\mathrm{a}}$ & $17.59 \pm 3.46^{\mathrm{a}}$ & I (BS, KMS) \\
\hline M. maximus & $3.17 \pm 0.60$ & $2.86 \pm 0.78$ & $10.50 \pm 2.13^{\mathrm{a}}$ & $16.59 \pm 2.02^{\mathrm{a}}$ & II (BS), I (KMS) \\
\hline P. miliaceum & ++ & ++ & $10.92 \pm 2.47^{\mathrm{a}}$ & $18.03 \pm 2.32^{\mathrm{a}}$ & II, III (BS), I (KMS) \\
\hline \multicolumn{6}{|l|}{$\mathrm{C}_{3}$ species } \\
\hline H. proluta & $2.10 \pm 0.96^{\mathrm{b}}$ & $4.33 \pm 1.59^{\mathrm{b}}$ & $1.59 \pm 0.53^{\mathrm{a}}$ & $4.26 \pm 1.84^{\mathrm{a}}$ & II, III (BS, M) \\
\hline P. australis & - & - & - & - & - \\
\hline P. bisulcatum & + & + & + & $1.71 \pm 0.69$ & III (BS) \\
\hline T. aestivum & $1.93 \pm 0.96$ & $2.23 \pm 1.21$ & $1.90 \pm 0.98$ & $1.83 \pm 0.71$ & II, III (BS, M) \\
\hline
\end{tabular}

Values for BS chloroplasts and for $\mathrm{M}$ cells of $\mathrm{C}_{3}$ species are only estimates, mean $\pm \mathrm{SD}$ are shown. + , single vesicles or groups of vesicles in some plastids only; ++ , single vesicles or groups of vesicles in most plastids. PR classification after Wise and Harris (1984)

Data significance: ${ }^{\mathrm{a}} p<0.001 ;{ }^{\mathrm{b}} p<0.05$; unpaired $t$ test
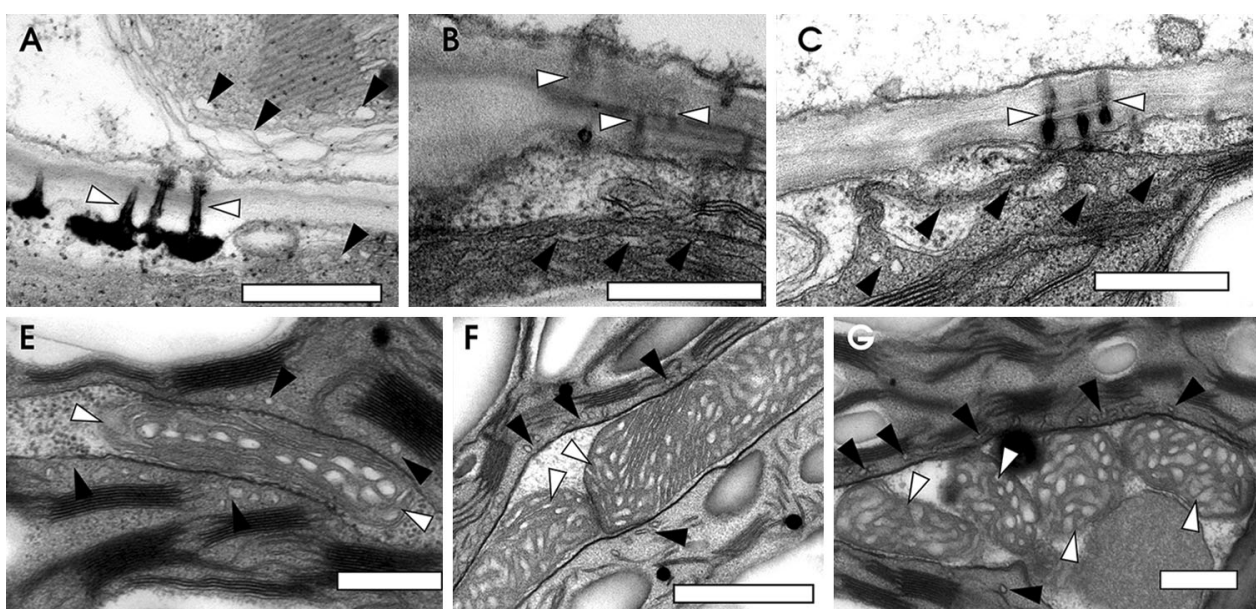

Fig. 4 The contact of the chloroplast peripheral reticulum (PR) with the Kranz mesophyll/bundle sheath plasmodesmata (KMS/BS PD, a-d) and mitochondria in bundle sheath cells $(\mathbf{e}-\mathbf{h})$ in four different species of $\mathrm{C}_{4}$ grasses. In a-d KMS cells are always up. The black arrowheads always show PR, while the white arrowheads point either PD (a-d) or mitochondria (e-h). All photographs were taken from the interesting result of ours is a strong negative correlation between the size of PR in KMS plastids and the perimeter to area ratio (Table 3). That means, PR increases in size in chloroplasts with low perimeter/area ratio (and probably low surface/area ratio). By increasing overall surface of the chloroplast inner envelope, PR may enhance transport capacity of the plastid's membranes (Wise 2006). Differences in correlation strength between individual species may reflect anatomical differences, such as relative size and number of KMS and BS chloroplasts, or Kranz anatomy type. At the same time, there was low correlation

occupied by the PR) of eight different $\mathrm{C}_{4}$ and $\mathrm{C}_{3}$ grasses grown at light intensities of 100 and $500 \mu \mathrm{mol}$ quanta $\mathrm{m}^{-2} \mathrm{~s}^{-1}$ 
Table 3 Correlations between the area of the chloroplast cross-section occupied by the peripheral reticulum (PRA) and: the perimeter to area ratio (PARA), roundness $(R)$ or compactness $(C)$ of the chloroplast in KMS cells of four different $\mathrm{C}_{4}$ grasses grown at two light intensities, expressed as Pearson product-moment correlation coefficients

\begin{tabular}{|c|c|c|c|c|}
\hline \multirow[t]{2}{*}{ Species } & \multirow{2}{*}{$\begin{array}{l}\text { Light intensity } \\
(\mu \mathrm{mol} \text { quanta } \\
\left.\mathrm{m}^{-2} \mathrm{~s}^{-1}\right)\end{array}$} & \multicolumn{3}{|c|}{ Compared variables } \\
\hline & & $\begin{array}{l}\text { PRA vs } \\
\text { PARA }\end{array}$ & $\begin{array}{l}\text { PRA vs } \\
R\end{array}$ & $\begin{array}{l}\text { PRA vs } \\
C\end{array}$ \\
\hline \multirow[t]{2}{*}{ E. albensis } & 100 & $-0.30^{\mathrm{a}}$ & -0.36 & $0.41^{\mathrm{a}}$ \\
\hline & 500 & $-0.58^{\mathrm{a}}$ & -0.17 & 0.22 \\
\hline \multirow[t]{2}{*}{ E. crus-galli } & 100 & $-0.48^{\mathrm{a}}$ & 0.14 & 0.07 \\
\hline & 500 & $-0.58^{\mathrm{a}}$ & 0.17 & 0.22 \\
\hline \multirow[t]{2}{*}{ M. maximus } & 100 & $-0.50^{\mathrm{a}}$ & $0.19^{\mathrm{a}}$ & 0.82 \\
\hline & 500 & $-0.68^{a}$ & -0.22 & 0.26 \\
\hline \multirow[t]{2}{*}{ P. miliaceum } & 100 & $-0.65^{\mathrm{a}}$ & -0.08 & $0.42^{\mathrm{a}}$ \\
\hline & 500 & $-0.72^{\mathrm{a}}$ & 0.50 & $-0.05^{\mathrm{a}}$ \\
\hline
\end{tabular}

${ }^{a}$ Data significant with $p<0.05$

between PR area and shape parameters, such as roundness or compactness, implying that PR size does not depend on chloroplast shape and/or the angle at which the cross-section was made.

These results point to the possible role of PR in transport capacity of the KMS plastids. For $\mathrm{C}_{4}$ plants, light intensity during growth is proportional to carbon assimilation rate, plasmodesmatal density at KMS/BS interface, and photosynthate export rate (Sowiński et al. 2007). It seems that PR appears (or rather increases in size) wherever there is a need for an increased demand for transport in and out of the plastid: aging (Almela et al. 1996), stress conditions (Kratsch and Wise 2000; Proctor et al. 2007), and the leaves of $\mathrm{C}_{4}$ plants (Osmond 1971) are the examples of such a system.

The role of PR as an adaptation for increased transport demands into and out of the chloroplast in the $\mathrm{C} 4$ plants is reinforced by the observations made by Evert et al. (1977), who noticed that PR in both cell types was sometimes in close contact with PD and the ER associated with these structures. We observed such situations for different types of PD in KMS and BS cells (but not for PD between BS and vascular cells). However, such arrangement was found only for about one in ten PD at a given cell interface. In accordance with earlier observations, we found that PR (almost exclusively in BS cells) is enlarged near mitochondria (Kursanov 1984). This was especially evident for NAD-ME and PEP-CK species, where this phenomenon was abundant.

Based on the presented results and literature survey, one can assume that PR participates in some light-dependent processes, preferentially in KMS cells. One of these processes could be metabolite exchange during $\mathrm{C}_{4}$ cycle, what remains in agreement with the hypothesis proposed shortly after discovery of the $\mathrm{C}_{4}$ metabolism (Gracen et al. 1972; Laetsch 1974). Association between PR and mitochondria in BS cells of NAD-ME and PEP-CK species, in which mitochondria are the main site for decarboxylation of $\mathrm{C}_{4}$ acids (Furbank et al. 2000), and the prevalence of PR in KMS chloroplasts seems to reinforce this claim. KMS plastids are the site for PEP regeneration (Leegood 2000). As this reaction, catalyzed by pyruvate phosphate dikinase (PPDK) is a limiting step for the whole $\mathrm{C}_{4}$ cycle (Wang et al. 2008), appropriate metabolite concentrations in KMS chloroplasts must be vital for the whole process (Leegood 1985). By increasing chloroplast surface available for transport, PR in KMS chloroplasts may contribute to pyruvate/PEP exchange with the help of specific transporters (Brautigam and Weber 2011; Majeran and van Wijk 2009). Increased content of PR in BS chloroplasts of E. crus-galli (Fig. 2) can reflect increased demands for metabolite exchange through BS chloroplast envelope. E. crus-galli is the only studied species representing NADP-ME subtype of $\mathrm{C}_{4}$ photosynthesis. In contrast to other variants of $\mathrm{C}_{4}$ biochemistry, here, both $\mathrm{KMS}$ and $\mathrm{BS}$ chloroplasts take active part in the operation of $\mathrm{C}_{4}$ cycle (Furbank 2011). PR type I was also observed in BS chloroplasts of other NADP-ME species, such as maize (Gracen et al. 1972) or NADP-ME and NAD-ME C 4 sedges (Bruhl and Perry 1995; Ueno et al. 1988). It is interesting that PR type I was found in BS cells of the sedges with eleocharoid, chlorocyperoid and fimbristyloid anatomy, but not in species with rhynchosporoid anatomy. In all but rhynchosporoid Kranz anatomy types found in sedges, BS cells are separated from KMS cells by an additional layer of non-photosynthetic mestome sheath cells (Edwards and Voznesenskaya 2011), what probably requires more efficient transport between both photosynthetic cells (Bruhl and Perry 1995). Kranz anatomies similar to those of chlorocyperoid or fimbristyloid sedges are also found in some grasses (Voznesenskaya et al. 2005). However, nothing is known about the occurrence and form of PR in BS chloroplasts of these species.

In summary, the occurrence chloroplast PR in grasses follows photosynthetic type-dependent pattern, but not a phylogenetic one. Its most elaborated form-PR type Ican be treated as a unique feature of $\mathrm{C}_{4}$ species. Several lines of evidence, such as light-dependence of PR size, negative correlation between PR size and plastid surface available for metabolite exchange, and associations with mitochondria and PD connecting cells participating in $\mathrm{C}_{4}$ cycle, point to the conclusion that $\mathrm{PR}$ may be a vital player in metabolite transport during $\mathrm{C}_{4}$ photosynthesis. However, the presented results are only indirect hints which can also imply that PR participates in transport processes other than $\mathrm{C}_{4}$ cycle (e.g., in sucrose synthesis). Further studies, 
including cytolocalization of $\mathrm{C}_{4}$ intermediate transporters in relation to light regime, or the use of specific inhibitors, are needed to support this hypothesis.

Author contribution Study design-JS, PS; material sampling, microscopy protocols, biometric analysis-JS; data analysis and manuscript preparation-PS.

Open Access This article is distributed under the terms of the Creative Commons Attribution License which permits any use, distribution, and reproduction in any medium, provided the original author(s) and the source are credited.

\section{References}

Almela L, Fernandez-Lopez JA, Candela ME, Egea C, Alcazar MD (1996) Changes in pigments, chlorophyllase activity, and chloroplast ultrastructure in ripening pepper for paprika. Agric Food Chem 44:1704-1711. doi:10.1021/jf9504531

Black CC, Mollenhauer HH (1971) Structure and distribution of chloroplasts and other organelles in leaves with various rates of photosynthesis. Plant Physiol 47:15-23

Brautigam A, Weber APM (2011) Transport processes: connecting the reactions of $\mathrm{C}_{4}$ photosynthesis. In: Raghavendra AS, Sage $\mathrm{RF}$ (eds) $\mathrm{C}_{4}$ photosynthesis and related $\mathrm{CO}_{2}$ concentrating mechanisms. Springer, Dordrecht, pp 199-219

Bruhl J, Perry S (1995) Photosynthetic pathway-related ultrastructure of $\mathrm{C}_{3}, \mathrm{C}_{4}$ and $\mathrm{C}_{3}$-like $\mathrm{C}_{3}-\mathrm{C}_{4}$ intermediate sedges (Cyperaceae), with special reference to Eleocharis. Aust J Plant Physiol 22:521-530

Chapman EA, Bain JM, Gove DW (1975) Mitochondria and chloroplast peripheral reticulum in the $\mathrm{C}_{4}$ plants Amaranthus edulis and Atriplex spongiosa. Aust J Plant Physiol 2:207-223

Drożak A, Romanowska E (2006) Acclimation of mesophyll and bundle sheath chloroplasts of maize to different irradiances during growth. Biochim Biophys Acta 1757(11):1539-1546

Edwards GE, Voznesenskaya EV (2011) $\mathrm{C}_{4}$ photosynthesis: Kranz forms and single-cell $\mathrm{C}_{4}$ in terrestrial plants. In: Raghavendra $\mathrm{AS}$, Sage RF (eds) $\mathrm{C}_{4}$ photosynthesis and related $\mathrm{CO}_{2}$ concentrating mechanisms. Springer, Dordrecht, pp 29-61

Evert RF, Eschrich W, Heyser W (1977) Distribution and structure of the plasmodesmata in mesophyll and bundle-sheath cells of Zea mays L. Planta 136:77-89

Furbank RT (2011) Evolution of the $\mathrm{C}_{4}$ photosynthetic mechanism: are there really three $\mathrm{C}_{4}$ acid decarboxylation types? $\mathrm{J}$ Exp Bot 62:3103-3108. doi:10.1093/jxb/err080

Furbank RT, Hatch MD, Jenkins CLD (2000) $C_{4}$ photosynthesis: mechanism and regulation. In: Leegood RC, Sharkey TD, von Caemmerer S (eds) Photosynthesis: physiology and metabolism. Kluwer, Dordrecht, pp 435-457

Gracen VE, Hilliard JH, Brown RH, West SH (1972) Peripheral reticulum in chloroplasts of plants differing in $\mathrm{CO}_{2}$ fixation pathways and photorespiration. Planta 107:189-204

Grass Phylogeny Working Group II (2012) New grass phylogeny resolves deep evolutionary relationships and discovers $\mathrm{C}_{4}$ origins. New Phytol 193:304-312. doi:10.1111/j.1469-8137. 2011.03972.x

Heldt HW, Saur F (1971) The inner membrane of the chloroplast envelope as a site of specific metabolite transport. Biochim Biophys Acta 243:83-91

Hepler PK (1982) Endoplasmic reticulum in the formation of the cell plate and plasmodesmata. Protoplasma 111:121-133
Hilliard JH, West SH (1971) The association of chloroplast peripheral reticulum with low photorespiration rates in a photorespiring plant species. Planta 99:352-356

Jończyk M, Sobkowiak A, Siedlecki P, Biecek P, TrzcińskaDanielewicz J, Tiuryn J, Fronk J, Sowiński P (2011) Rhythmic diel pattern of gene expression in juvenile maize leaf. PLoS One 6(8):e23628. doi:10.1371/journal.pone.0023628

Kratsch HA, Wise RR (2000) The ultrastructure of chilling stress. Plant Cell Environ 23:337-350. doi:10.1046/j.1365-3040.2000. 00560.x

Kursanov AL (1984) Assimilate transport in plants. Elsevier, Amsterdam

Laetsch WM (1974) The $C_{4}$ syndrome: a structural analysis. Ann Rev Plant Physiol 25:27-52

Lawton JR (1988) Ultrastructure of chloroplast membranes in leaves of maize and ryegrass as revealed by selective staining methods. New Phytol 108:277-283

Leegood RC (1985) The intercellular compartmentation of metabolites in leaves of Zea mays L. Planta 164:163-171

Leegood RC (2000) Transport during $\mathrm{C}_{4}$ photosynthesis. In: Leegood RC, Sharkey TD, von Caemmerer S (eds) Photosynthesis: physiology and metabolism. Kluwer, Dordrecht, pp 459-469

Liu Y, Dengler NG (1994) Bundle sheath and mesophyll cell differentiation in the $\mathrm{C}_{4}$ dicotyledon Atriplex rosea: quantitative ultrastructure. Can J Bot 72:644-657

Majeran W, van Wijk KJ (2009) Cell-type-specific differentiation of chloroplasts in $\mathrm{C}_{4}$ plants. Trends Plant Sci 14:100-109. doi:10. 1016/j.tplants.2008.11.006

Montero RS, Bribiesca E (2009) State of the art of compactness and circularity measures. Int Math Forum 4:1305-1335

Mosejev VV, Romanovskaya OO, Iljin VV (1987) Electron-cytochemical osmium-ferricyanide staining of cereal chloroplasts. Protoplasma 140:22-25

Osmond CB (1971) Metabolite transport in $\mathrm{C}_{4}$ photosynthesis. Aust J Biol Sci 24:159-163

Pearcy RW, Franceschi VR (1986) Photosynthetic characteristics and chloroplast ultrastructure of $\mathrm{C}_{3}$ and $\mathrm{C}_{4}$ tree species grown in lowand high-light environments. Photosynth Res 9:317-331

Proctor MCF, Ligrone R, Duckett JG (2007) Desiccation tolerance in the moss Polytrichum formosum: physiological and fine-structural changes during desiccation and recovery. Ann Bot 99:345-353. doi:10.1093/aob/mcm096

Rosado-Alberio J, Weier TE, Stocking CR (1968) Continuity of the chloroplast membrane systems in Zea mays L. Plant Physiol 43:1325-1331

Shumway LK, Weier TE (1967) The chloroplast structure of Iojap maize. Am J Bot 54:773-780

Slack CR, Hatch MD, Goodchild DJ (1969) Distribution of enzymes in mesophyll and parenchyma-sheath chloroplasts of maize leaves in relation to the $\mathrm{C}_{4}$-dicarboxylic acid pathway of photosynthesis. Biochem J 114:489-498

Sowiński P, Bilska A, Barańska K, Fronk J, Kobus P (2007) Plasmodesmata density in vascular bundles in leaves of $\mathrm{C}_{4}$ grasses grown at different light conditions in respect to photosynthesis and photosynthate export efficiency. Environ Exp Bot 61:74-84. doi:10.1016/j.envexpbot.2007.03.00

Ueno O, Takeda T, Maeda E (1988) Leaf ultrastructure of $\mathrm{C}_{4}$ species possessing different Kranz anatomical types in the Cyperaceae. Bot Mag Tokyo 101:141-152

Voznesenskaya EV, Chuong SDX, Koteyeva NK, Edwards GE, Franceschi VR (2005) Functional compartmentation of $\mathrm{C}_{4}$ photosynthesis in the triple-layered chlorenchyma of Aristida (Poaceae). Funct Plant Biol 32:67-77. doi:10.1071/FP04118

Walters RG (2005) Towards an understanding of photosynthetic acclimation. J Exp Bot 56:435-447. doi:10.1093/jxb/eri060 
Wang D, Portis AR, Moose SP, Long SP (2008) Cool C 4 photosynthesis: pyruvate $\mathrm{P}_{\mathrm{i}}$ dikinase expression and activity corresponds to the exceptional cold tolerance of carbon assimilation in Miscanthus $\times$ giganteus. Plant Physiol 148:557-567. doi:10. 1104/pp.108.120709

Westphal S, Soll J, Vothknecht UC (2003) Evolution of chloroplast vesicle transport. Plant Cell Physiol 44:217-222. doi:10.1093/ $\mathrm{pcp} / \mathrm{pcg} 023$
Wise RR (2006) The diversity of plastid form and function. In: Wise RR, Hoober JK (eds) The structure and function of plastids. Springer, Dordrecht, pp 3-26

Wise RR, Harris JB (1984) The three-dimensional structure of the Cyphomandra betacea chloroplast peripheral reticulum. Protoplasma 119:222-225 